\title{
Bir Fazlı Paralel Aktif Güç Filtresi Modeli ve Denetimi
}

\author{
Zeynep Bala DURANAY ${ }^{1 *}$, Hanifi GÜLDEMIR ${ }^{2}$ \\ ${ }^{1,2}$ Elektrik-Elektronik Mühendisliği, Teknoloji Fakültesi, Fırat Üniversitesi, Elazı̆ğ, Türkiye \\ *1zbduranay@firat.edu.tr, 22hguldemir@firat.edu.tr
}

Öz: Şebekeden çekilen reaktif güç ve harmonikler güç kalitesi problemini oluşturmaktadır. Bu problemler aktif güç filtresi olarak bilinen güç elektroniği devrelerinin uygun algoritmalar kullanılarak denetlenmesiyle büyük oranda iyileştirilebilmektedir. Bu çalışmada bir fazlı paralel aktif güç filtresi modeli oluşturulmuştur. Bu paralel aktif güç filtresinin denetimi histerisiz bant akım denetim yöntemi kullanılan bir evirici ile yapılmıștır. Sistem p-q teorisi tabanlı olup bu teori bir fazlı sisteme göre uyarlanmıştır. Tüm sistem Matlab/Simulink' te oluşturulmuş olup hem paralel aktif güç filtresi devre dışı iken, hem de devreye alındıktan sonra elde edilen akım dalga şekilleri gösterilmiş̧ir. Kullanılan paralel aktif güç filtresi ile harmoniklerin bastırıldığg ve güç kalitesindeki iyileşmenin açık olarak görüldüğü sonuçlar verilmiştir.

Anahtar kelimeler: Aktif güç filtresi, harmonik bastırma, histerisiz akım denetleyici, reaktif güç kompanzasyonu.

\section{Modelling and Control of Single Phase Parallel Active Power Filter}

\begin{abstract}
Reactive power and harmonics drawn from the network cause the power quality problems. These problems can be greatly improved by controlling the power electronics circuits known as active power filters using appropriate algorithms. In this study, a single-phase parallel active power filter model is modelled. The control of this parallel active power filter is made by an inverter using the hysteresis band current control method. The system is based on the $\mathrm{p}-\mathrm{q}$ theory and is adapted to the single-phase system. The whole system has been implemented in Matlab / Simulink and the current waveforms are presented both when the parallel active power filter is deactivated and after activated. Results clearly show that the parallel active power filter suppresses the harmonics of the supply current and also improves the power quality.
\end{abstract}

Key words: Active power filter, harmonic suppression, hysteresis current controller, reactive power compensation.

\section{Giriş}

Endüstride kullanılan doğrusal olmayan yükler elektrik şebekelerinde güç kalitesi problemlerini ortaya çıkarmıştır [1]. Güç kalitesi problemi alıcıların bozulmasına ya da yanlış çalışmasına sebep olan gerilim, akım veya frekans sapmalarıdır. Aydınlatma armatürleri, bilgisayarlar, kesintisiz güç kaynakları, doğrultucular ve değişken hızlı motor sürücüleri gibi güç elektroniği içeren devreler güç kalitesi problemlerine sebep olan doğrusal olmayan yüklere örnek olarak verilebilmektedir.

Güç elektroniği devrelerinin doğrusal olmayan özelliğinin oluşturduğu bu güç kalitesi problemi için pasif filtreler, kondansatörler, faz kaydırıcılar gibi geleneksel yöntemler kullanılmış olup bu tekniklerin maliyetlerinin ucuz ve yapılarının basit olması gibi avantajlarının yanında, sabit kompanzasyon, hantallık ve elektromanyetik girişim gibi dezavantajları [2] araştırmacıları bu probleme yönelik yüksek performanslı ayarlanabilir ve dinamik çözümler geliştirmeye yöneltmiştir. Bu çözümlerden biri Aktif Güç Filtresi (AGF) kullanmaktır [3]. Bağlantı şekline göre AGF' ler Paralel Aktif Güç Filtresi (PAGF), Seri Aktif Güç Filtresi (SAGF) ve Hibrit (karma) Aktif Güç Filtresi (HAGF) olarak isimler almaktadır. Bu AGF' ler arasında yaygın olarak kullanılanı PAGF' lerdir [4, $5]$.

PAGF doğrusal olmayan yüke paralel bağlı akım kontrollü bir gerilim kaynaklı evirici gibi çalışmaktadır. PAGF' ler geleneksel yöntemlerde olduğu gibi sadece belli frekanslardaki harmonikler için kullanılmazlar. Belli sınırlar dahilinde değişen işletme şartlarını karşılayabilmektedirler [6].

Uygun kontrol yöntemleri ile paralel aktif filtreler harmonik akımların bastırılması ve reaktif güç kompanzasyonu için kullanılabilmektedir [7]. Aktif filtreler gerilim harmoniklerinin, ve dalgalanmalarının bastırılması, yük üzerindeki gerilimin regülasyonu, güç sistemi gerilim dengesi ve rezonans sönümü için kullanılabilmektedir [8].

\footnotetext{
* Sorumlu yazar: zbduranay@ firat.edu.tr. Yazarların ORCID Numarası: ${ }^{1}$ 0000-0003-2212-5544, ${ }^{2}$ 0000-0003-0491-8348
} 
Bir PAGF güç devresi, ölçme devresi ve kontrol devrelerini içermektedir. Kontrol devresinin görevi, PAGF akımını istenilen şekilde elde edilmesini sağlamaktır. İyi bir filtre performansı için uygun bir referans akım elde edilmelidir. Bunun için farklı teknikler kullanılmakta olup bu çalışmada basit ve dayanıklı yapısı, kolay uygulanabilir olması ve hızlı dinamik cevabı gibi özelliklere sahip olmasından dolayı histerisiz bant akım denetleyici kullanılmıştır [9-11].

Aktif güç filtreleri üç fazlı ve bir fazlı sistemler için kullanılabilmektedir. Endüstride genellikle büyük güçlü sistemler kullanıldığından üç fazlı ancak düşük güçlü uygulamalarda ise bir fazlı aktif filtreler kullanılmaktadır.

Bu çalışmada, basit bir yapıya sahip olan anlık reaktif güç teorisi (p-q teorisi) [12-14] kullanılarak PAGF akımının kontrolü için gerekli olan referans işaretler elde edilmiştir. Matlab/Simulink programlama ortamı kullanılarak PAGF modellenmiştir. Modelden elde edilen PAGF' nin dinamik performansını gösteren benzetim sonuçları verilmiştir. Sonuçlardan düşük toplam harmonik bozulmanın ve birim güç faktörü değerinin sağlandığı görülmüştür.

\section{Paralel Aktif Güç Filtresi}

Paralel aktif güç filtresinin temel görevi yükün ihtiyaç duyduğu reaktif gücü yerel olarak sağlayarak şebekede oluşan harmoniklerin bastırılmasıdır. Bu durumda kaynak sadece birim güç faktörlü dengeli sinüzoidal akımları sağlayacaktır. Bunu sağlamak için doğrusal olmayan yükün şebekeden çektiği akımdaki harmoniklerle aynı genlikte fakat ters fazda olan harmonikli bir akım şebekeye enjekte edilir [15]. Bu şekilde şebekeden çekilen akımdaki harmonikler yok edilerek akımın dalga şeklinin sinüzoidal formda olması sağlanmaktadır. Şekil 1' de PAGF prensip şeması ve Şekil 2' de ise akımların dalga şekilleri verilmiştir.

Aktif güç filtresi için gerekli akımlar, yük akımı, da bara gerilimi ve kaynak geriliminin algılanmasıyla tahmin edilmektedir [16, 17].

Şekil 3, PAGF' nin blok diyagramını göstermektedir. PAGF da kondansatöre sahip gerilim beslemeli evirici, filtre akımının şebekeye iletilmesi için bir bağlantı indüktansı ve filtrenin kompanzasyon akım işaretlerini üretebilmesi için bir denetleyici içermektedir.

Kaynaktan çekilen akım yani şebeke akımı is;

$i_{S}=i_{L}+i_{f}$

olmak üzere yükün kaynaktan çektiği akım $i_{L}$, ve filtre akımı $i_{f}$ den oluşmaktadır. Yük akımı harmonik bileşenler de içerdiğinden,

$i_{L}=i_{L 1}+i_{L h}$

Burada $i_{\text {L1 }}$ yük akımının temel (da) bileşenini, $i_{\text {Lh }}$ ise harmonik bileşenlerini ifade eder. PAGF' nin amacı yük akımındaki harmonik bileşenlerle aynı genlikte fakat zıt fazda harmonik akımlar üretmek olduğundan filtre akımı

$i_{f}=-i_{L h}$

şeklinde yazılabilir.

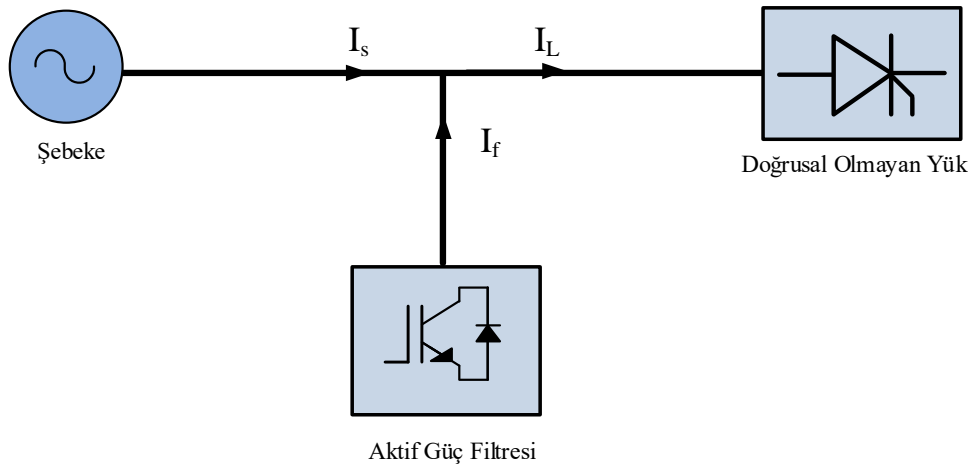

Şekil 1. PAGF prensip şeması. 

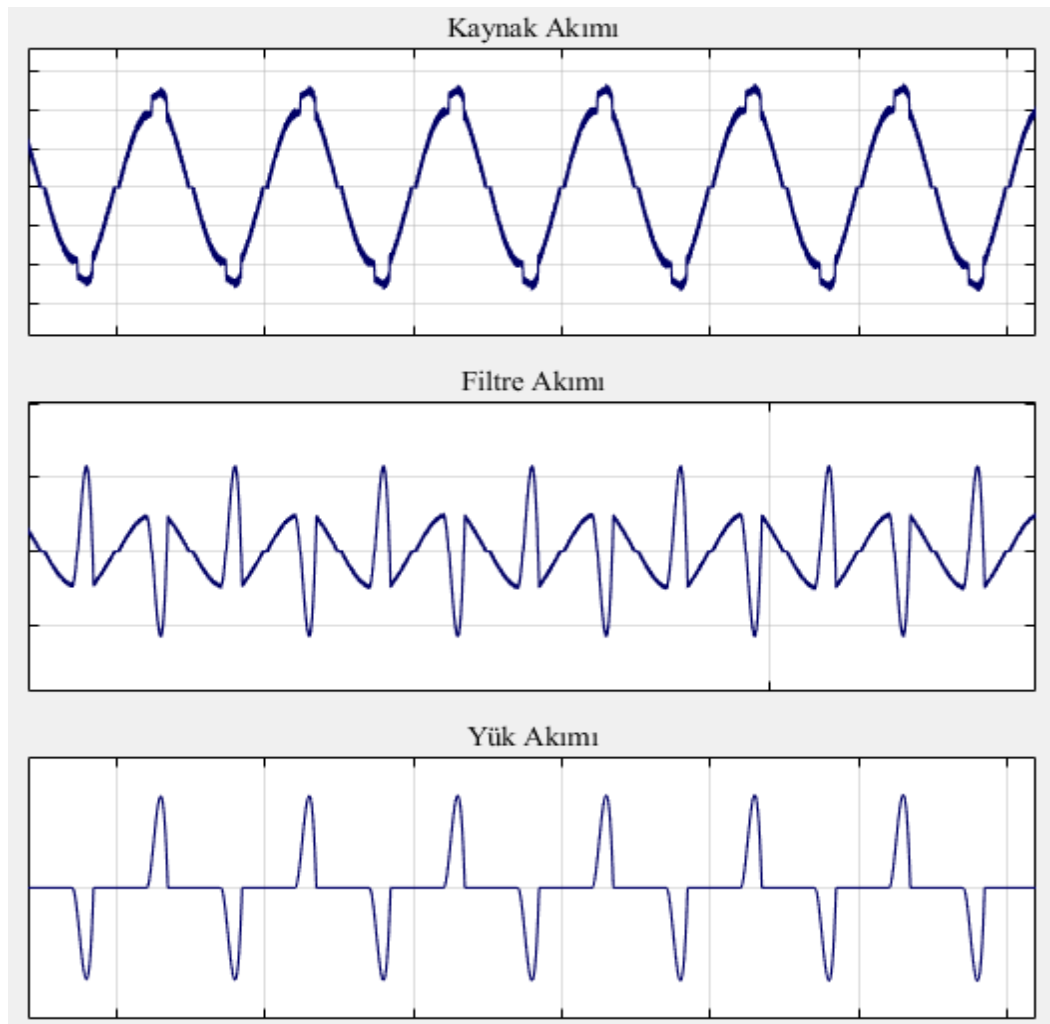

Şekil 2. Kaynak, aktif güç filtresi ve yük akımı dalga şekilleri.

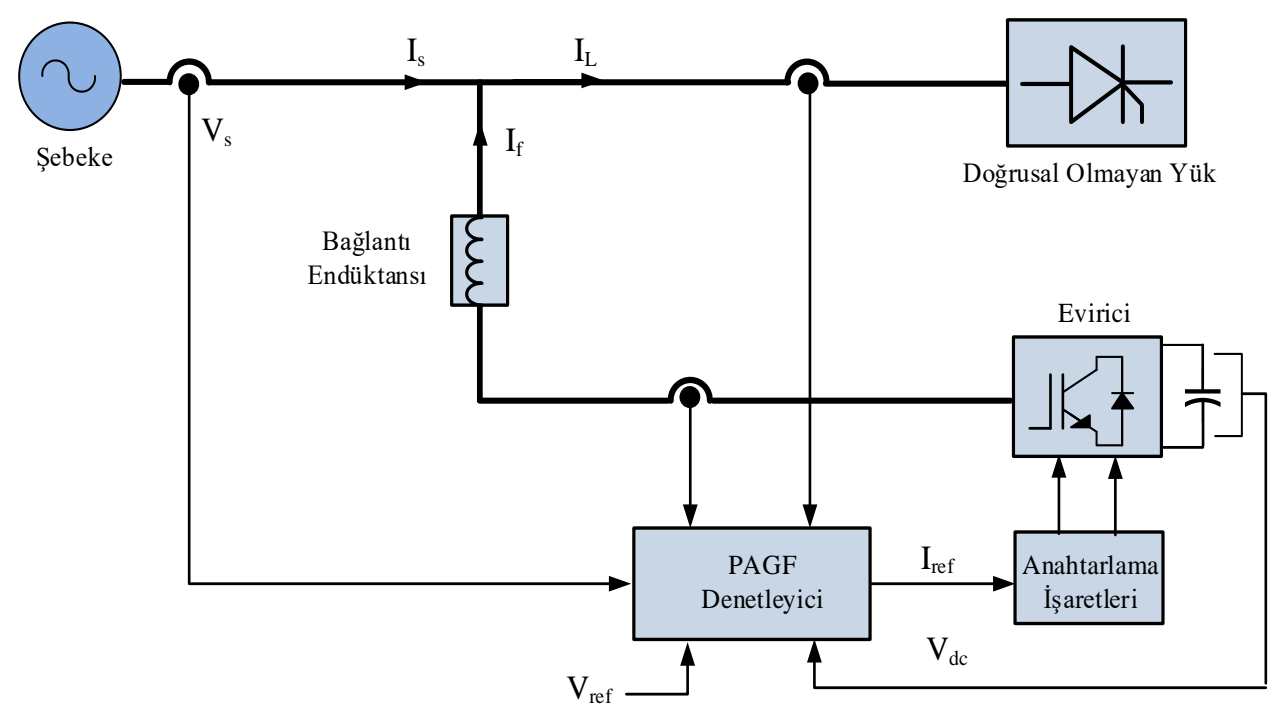

Şekil 3. PAGF blok diyagramı.

\section{PAGF Kontrolü}

PAGF' nin kontrolü $\alpha \beta 0$ referans eksen takımı kullanılarak yapılmıştır. Sistem gerilimi ve yük akımı Clarke dönüşümleri kullanılarak sadece $\alpha$ ve $\beta$ bileşenleri Denklem (4) ve Denklem (5) ifadeleri ile bu eksen takımında ifade edilmiştir. 


$$
\begin{aligned}
& {\left[\begin{array}{l}
v_{s \alpha} \\
v_{s \beta}
\end{array}\right]=\sqrt{\frac{2}{3}} \times\left[\begin{array}{ccc}
1 & -1 / 2 & -1 / 2 \\
0 & \sqrt{3} / 2 & -\sqrt{3} / 2
\end{array}\right] \times\left[\begin{array}{l}
v_{s a} \\
v_{s b} \\
v_{s c}
\end{array}\right]} \\
& {\left[\begin{array}{l}
i_{L \alpha} \\
i_{L \beta}
\end{array}\right]=\sqrt{\frac{2}{3}} \times\left[\begin{array}{ccc}
1 & -1 / 2 & -1 / 2 \\
0 & \sqrt{3} / 2 & -\sqrt{3} / 2
\end{array}\right] \times\left[\begin{array}{l}
i_{L a} \\
i_{L b} \\
i_{L c}
\end{array}\right]}
\end{aligned}
$$

Ani reaktif güç teorisi sadece üç fazlı sistemlere uygulanabilmektedir. Bu teorinin bir fazlı sisteme uyarlanması genlikleri ölçülen akım ve gerilimle aynı ancak $\pm 120^{\circ}$ faz farklı iki sanal akım ve gerilim kullanılarak sanal üç fazlı sistem oluşturulur.

Bundan sonraki işlemler üç fazlı sistemlerle aynıdır. Hesaplamalar sonrasında sadece bir referans akım kullanılarak evirici kontrol edilir.

p-q teorisinde ani güç ifadesi;

$\left[\begin{array}{l}p \\ q\end{array}\right]=\left[\begin{array}{cc}v_{S \alpha} & v_{S \beta} \\ v_{S \beta} & -v_{S \alpha}\end{array}\right] \times\left[\begin{array}{l}i_{L \alpha} \\ i_{L \beta}\end{array}\right]$

şeklinde verilir.

Dönüşüm sonrası aktif ve reaktif güç bileşenleri $\mathrm{p}$ ve $\mathrm{q}$ ise;

$p=v_{S \alpha} \cdot i_{L \alpha}+v_{S \beta} \cdot i_{L \beta}$

$q=v_{S \beta} \cdot i_{L \alpha}-v_{S \alpha} \cdot i_{L \beta}$

olarak ifade edilir

Reaktif güç bileşeni aktif güç filtresi tarafından sağlanacağından sadece ani aktif güç bileşeninin ortalama değeri $(\bar{p})$ istenmektedir. Aktif filtrenin sağlaması gereken referans akımları belirlemek için istenen güç bileşeni ile istenmeyen güç bileşeninin ayrıştırılması gerekmektedir.

$\mathrm{p}$-q teorisi ile elde edilen ani güç bileşenlerine ilaveten paralel aktif filtrenin da barası olan kondansatör gerilimini düzenleyen $p_{\text {reg }}$ olarak ifade edilen regülasyon gücü tanımlanmıştır. Bu kondansatör geriliminin kontrolü için bir PI denetleyici ve referans gerilim $\left(V_{r e f}\right)$ ile da kondansatör gerilimi $\left(v_{d a}\right)$ arasındaki fark (hata) kullanılmıştır.

$e(t)=V_{r e f}-v_{d a}$

$p_{\text {reg }}=K_{p} \cdot e(t)+K_{i} \cdot \int e(t) d t$

$\mathrm{Bu}$ şekilde eviricinin da kondansatör gerilimi sabit tutulmuştur. PI denetleyici da kondansatör geriliminin denetlenmesinde kullanılan en yaygın yöntemlerden biridir $[18,19]$. Denetleyici çıkışı referans akım işaretlerine eklenerek oluşan aktif güç kayıplarının şebekeden karşılanması sağlanmıştır.

$p_{\text {reg }}$ bileşenini $\mathrm{p}_{\mathrm{x}}$ içerdiğinden istenmeyen güç bileşeni değeri,

$p_{x}=(p-\bar{p})-p_{\text {reg }}=\tilde{p}-p_{\text {reg }}$

$q_{x}=q$

İstenmeyen güç bileşenlerinden faydalanarak Denklem (13) kullanılarak $\alpha \beta$ eksen takımında kompanzasyon akımları belirlenir. Kompanzasyon akımının sıfır bileşeni ise Denklem (14) kullanılarak doğrudan yük akımından elde edilir.

$\left[\begin{array}{l}i_{r e f \_} \alpha \\ i_{r e f \_} \beta\end{array}\right]=\frac{1}{v_{\alpha}^{2}+v_{\beta}^{2}} \times\left[\begin{array}{cc}v_{\alpha} & v_{\beta} \\ -v_{\beta} & v_{\alpha}\end{array}\right] \times\left[\begin{array}{l}p_{x} \\ q_{x}\end{array}\right]$

$i_{\text {ref } \_0}=i_{L 0}=\frac{1}{\sqrt{3}}\left(i_{L a}+i_{L b}+i_{L c}\right)$ 
Referans akımların abc koordinat sistemindeki eşdeğerleri, $\alpha \beta 0$ koordinat sistemindeki değerlerine ters Clarke dönüşümü uygulanarak elde edilir.

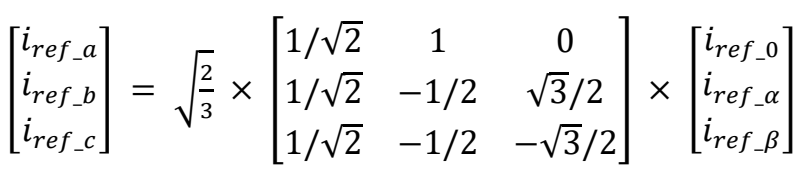

Şekil 4' de paralel aktif filtre denetiminin blok diyagramı verilmiştir.

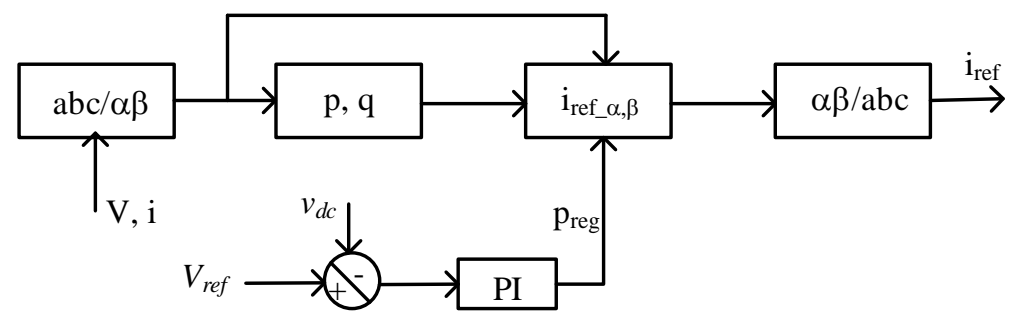

Şekil 4. Referans akım elde etme blok diyagramı.

Elde edilen bu referans akımlar ile eviricide kullanılan anahtarlama elemanları için anahtarlama işaretleri üretilir. Referans akımlar da ( $\bar{l}$ ) ve aa ( $\tilde{\imath})$ bileşenlerden oluşur.

$i=\bar{\imath}+\tilde{\imath}$

Akımdaki da işaretler temel bileşeni, aa işaretler ise harmonik bileşenleri ifade eder. Akımdaki aa işaretler yüksek geçiren bir filtre kullanılarak elde edilir. PAGF' nin denetimi için elde edilen bu referans işaretler ile harmonik bastırma işlemi gerçekleştirilir.

PAGF' de harmonik akımlar, evirici anahtarlarının uygun şekilde anahtarlanması ile oluşturulduğundan, referans işaretlerin doğru ve hızlı bir şekilde elde edilmesi oldukça önemlidir.

\section{Histerisiz Bant Akımı Denetimi}

Akım denetimi PAGF' nin performansına etki eden önemli faktörlerden biridir. Oluşturulan referans akımlar ile evirici anahtarlama elemanları için uygun anahtarlama işaretleri üretilmektedir. Uygulanabilirliğinin kolay olması, hızlı cevabı ve sistemde meydana gelen parametre değişimlerine duyarsız olması özelliğinden dolayı [20, 21] burada histerisiz band akım denetleyici kullanılmıştır.

$\mathrm{Bu}$ yöntemde, referans akımlar ile ölçülen evirici çıkış akımları karşılaştırılarak, hata işareti bir histerisiz bant karşılaştırıcıya girilir. Histerisiz bant karşılaştırıcının çıkışında evirici anahtarlama elemanları için darbe genişlik modülasyonlu anahtarlama işaretleri elde edilmiş olur. Histerisiz bant karşılaştırıcı genel blok şema Şekil 5' de, histerisiz bant karşılaştırma sonucu elde edilen darbe genişlik modülasyonlu işaret elde etme işlemi Şekil 6' da verilmiştir.

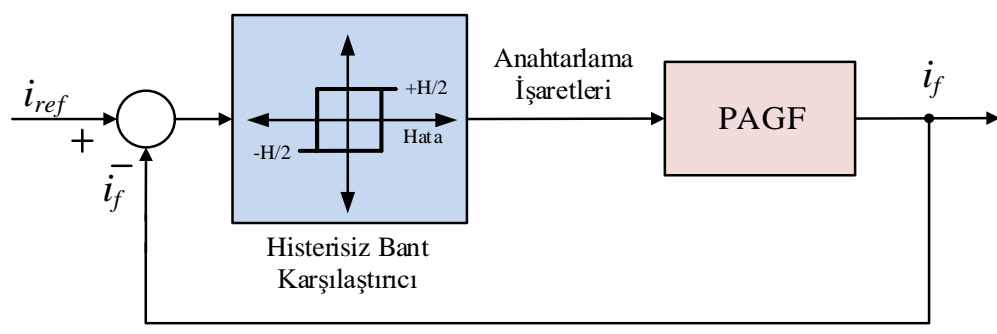

Şekil 5. Histerisiz bant akım denetimi blok diyagramı. 


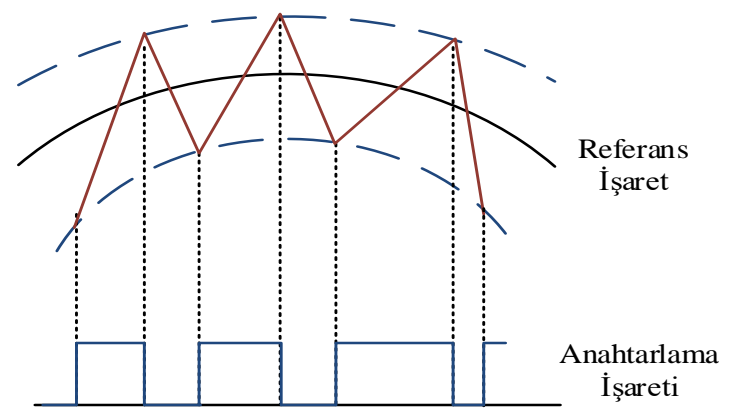

Şekil 6. Histerisiz bant anahtarlama işareti üretimi.

\section{Benzetim Sonuçları}

Şekil 3' te verilen PAGF Matlab-Simulink programlama ortamında modellenerek benzetimi yapılmıştır. Tüm sistemin Simulink modeli Şekil 7' de, benzetimde kullanılan parametreler ise Tablo 1' de verilmiştir. Doğrusal olmayan yük olarak köprü doğrultucuya bağlı bir RL yükü kullanılmıştır.

Tablo 1. Benzetimde kullanılan parametreler

\begin{tabular}{|l|l|}
\hline Da bara kondansatörü & $5 \mathrm{mF}$ \\
\hline Bağlantı İndüktans1 & $3.5 \mathrm{mH}$ \\
\hline Şebeke Gerilimi & $220 \mathrm{~V}$ \\
\hline Şebeke Frekans1 & $50 \mathrm{~Hz}$ \\
\hline Yük Direnci & $50 \Omega$ \\
\hline Yük İndüktans1 & $0.5 \mathrm{H}$ \\
\hline
\end{tabular}

Sistemin benzetimi yapılarak PAGF devre dışı iken ve devreye alındığında şebeke akımı, yük akımı ve filtre akımı izlenmiş ve sonuçlar verilmiştir.

Şekil 8’ de filtre 0.3. saniyede devreye alındığı durumdaki akımların dalga şekli gösterilmiştir.

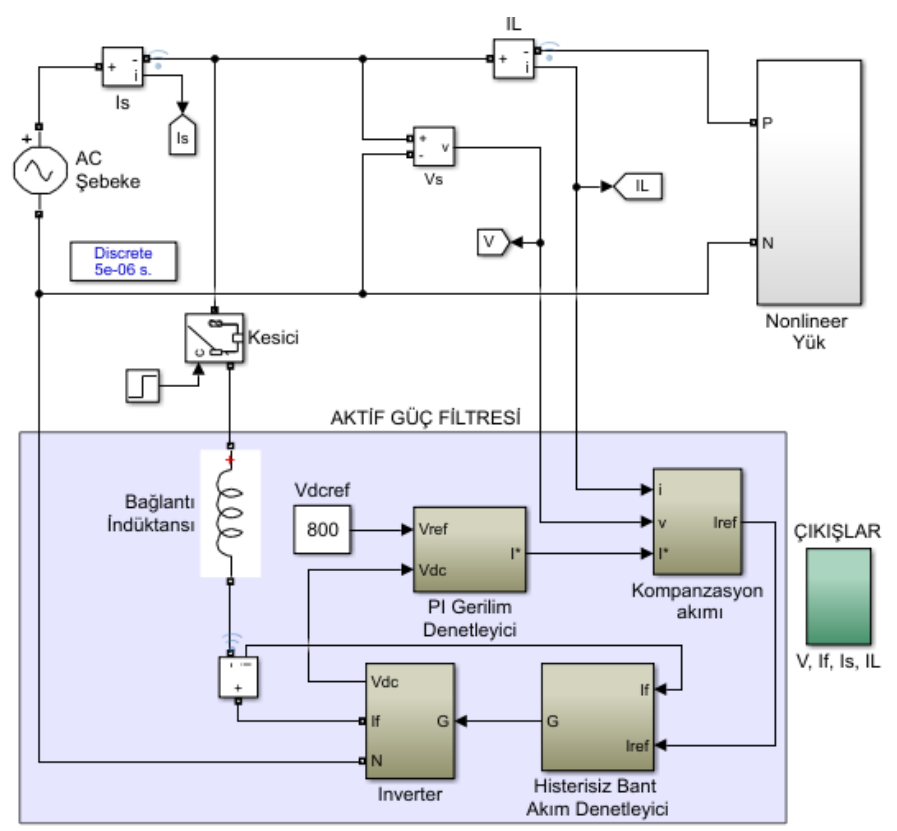

Şekil 7. PAGF Simulink modeli. 

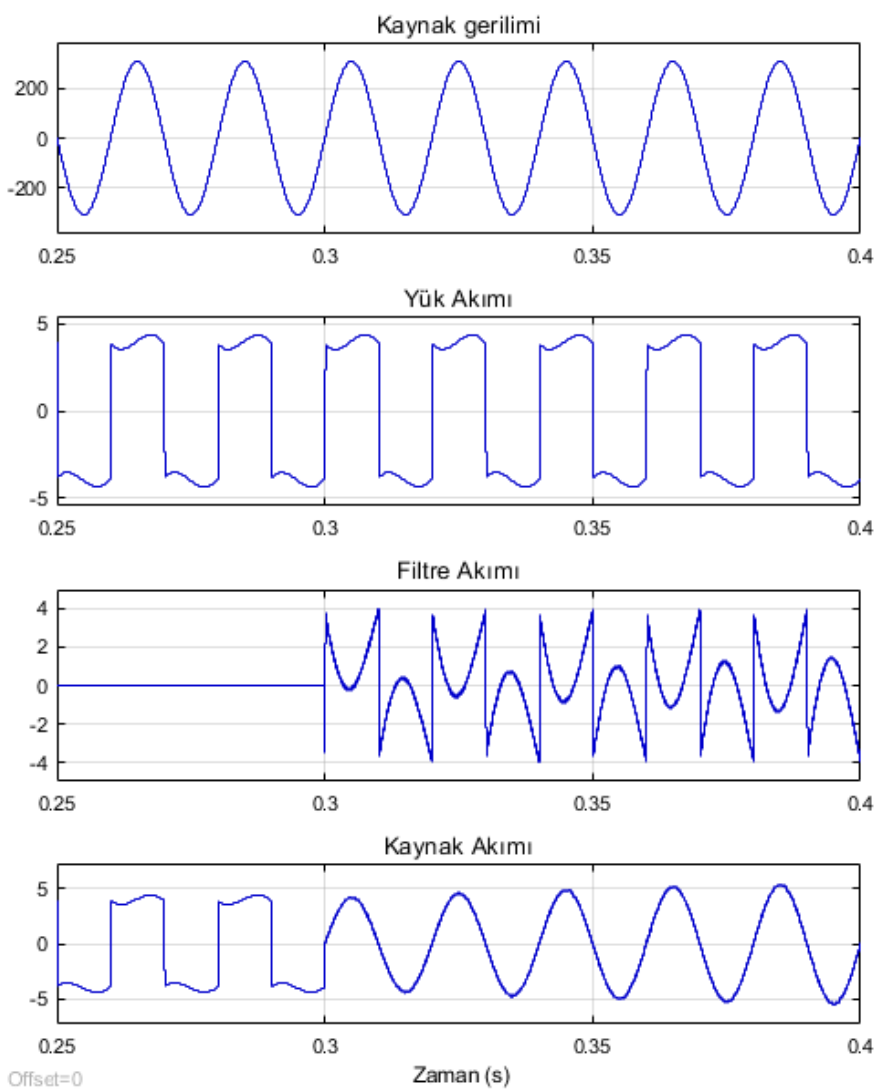

Şekil 8. PAGF kaynak, yük ve filtre akım dalga şekilleri.

Sistem normal çalışma durumunda yani filtre devre dışı iken doğrusal olmayan yükü besleyen şebekeden çekilen akımın harmonik içerikli olduğu, filtreden akım çekilmediği görülmektedir. Filtre devreye alındığında yükün ihtiyaç duyduğu reaktif güç PAGF tarafından sağlandığından şebeke akımındaki harmonikler bastırılmış ve şebeke akımı sinüzoidal forma yaklaşmıştır. Bu durumda şebeke akımının şebeke gerilimi ile aynı fazda olduğu da Şekil 9' da görülmektedir.

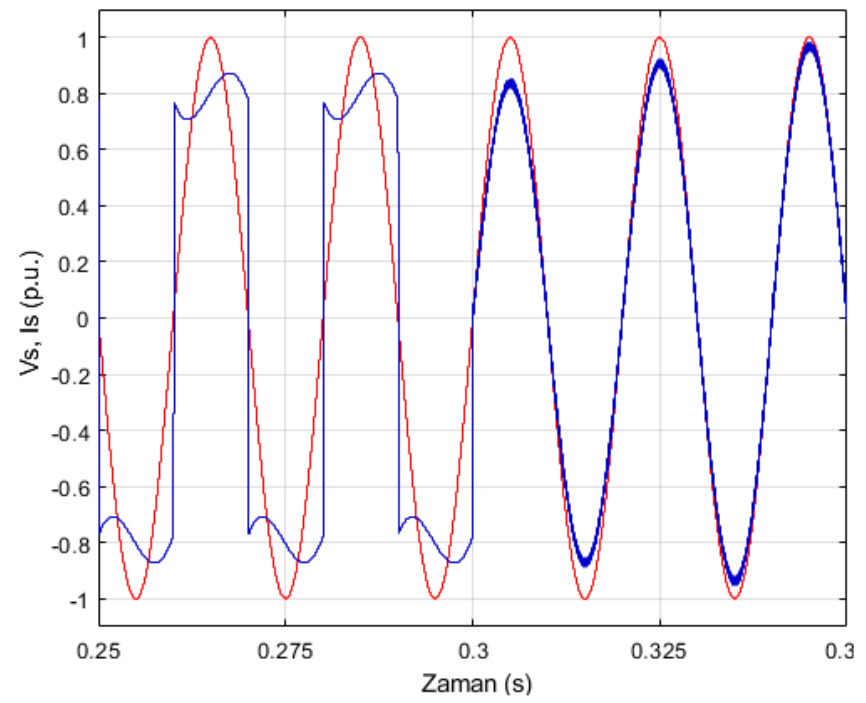

Şekil 9. PAGF kaynak, gerilim ve akım dalga şekilleri. 
Filtre hem devre dışı hem de devrede iken şebeke akımındaki harmonikler incelenmiş ve bu iki duruma ilişkin spektrum Şekil 10’ da verilmiştir.
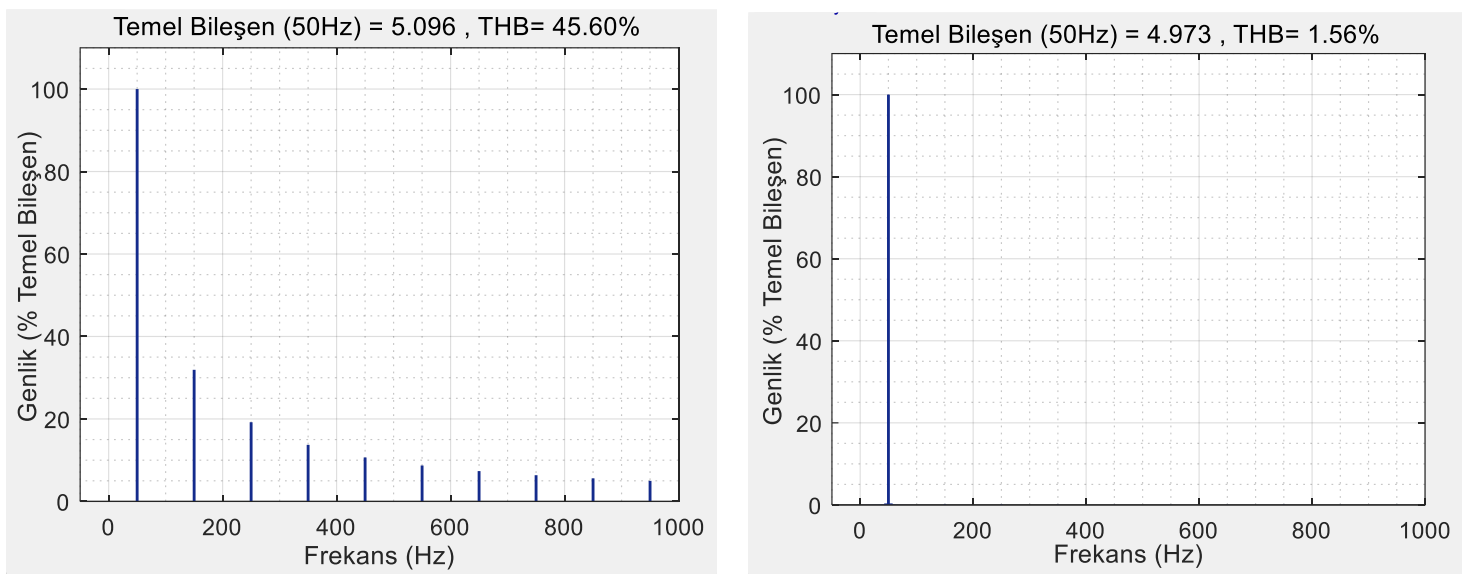

Şekil 10. (a) PAGF devre dışı iken (b) PAGF devreye alındığında kaynak akımı harmonik içeriği.

Elde edilen spektrumdan açıkça görüldüğü üzere filtresiz durumda $\% 45.6$ olan toplam harmonik bozulma filtre devreye girdiğinde \%1.56'ya düşmüștür. Filtre devreye alındığında kaynak akımı harmonik bileşenleri çok küçülmüș, bu bileşenleri görebilmek için Şekil 10 (b)' deki spektrumun genlik ekseni değeri düşürülerek Şekil 11' de verilmiştir.

Benzetim sonuçlarından görüldüğü üzere PAGF devreye alındığında şebekeden çekilen akım sinüzoidal forma yaklaşmış ve şebekenin yaklaşık birim güç faktöründe çalışması sağlanmıştır. Böylece PAGF kullanılarak hem reaktif güç kompanzasyonu hem de harmoniklerin bastırılması başarılı şekilde gerçekleştirilmiştir.

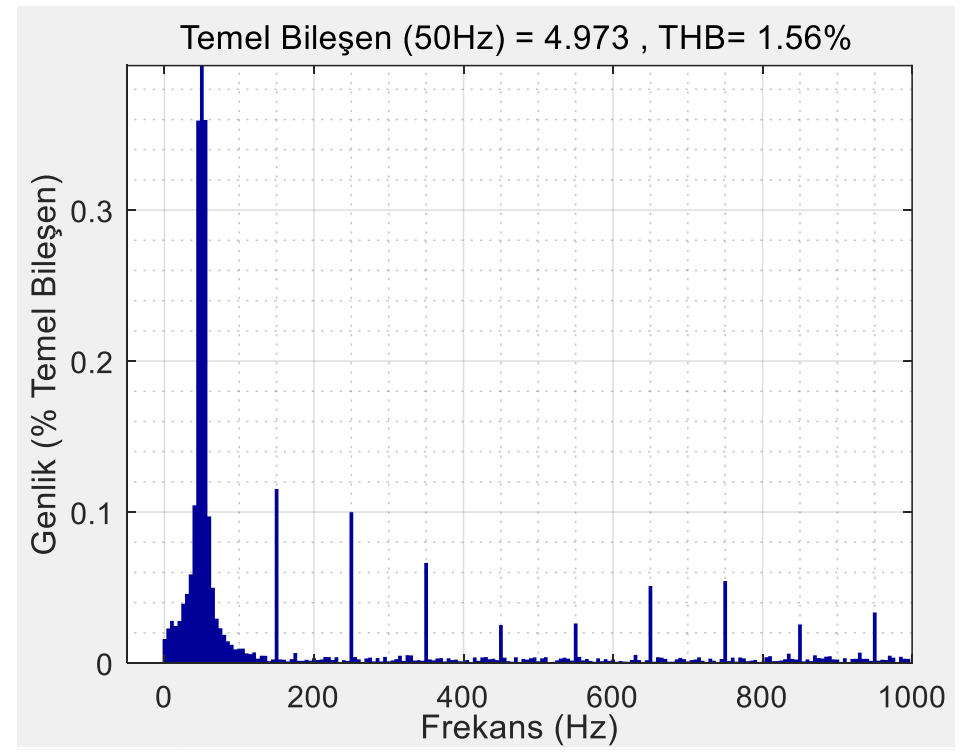

Şekil 11. PAGF devreye alındığında kaynak akımı harmonik içeriği büyütülmüş hali.

PAGF' nin hem reaktif güç kompanzasyonu yaptığı hem de harmonikleri bastırabildiğinin incelenmesi için kondansatör de içeren farklı bir doğrusal olmayan yük bağlanmış ve sistem çalıştırılarak 0.2. saniyede PAGF devreye alınmıștır. Bu durumda șebeke akım ve geriliminin p.u. değerleri zaman ekseni genişletilerek Șekil 12' de verilmiştir. 
Şekil 12' den açık bir şekilde görüldüğü üzere PAGF devreye alındığında akım dalga şekli sinüzoidal forma yaklaşarak harmonikler bastırılmış ve akım ile gerilim arasındaki faz farkı da giderilerek birim güç faktörüne yaklaşmıştır.

PAGF' nin performansı, evirici çıkış akımının referans işareti doğru bir şekilde izlemesine bağlıdır. Şekil 13 (a)' da referans işaret ve evirici çıkışında üretilen kompanzasyon akımına ait dalga şekilleri gösterilmiştir. Şekil 13 (b) ise Şekil 13 (a)' nın büyütülmüş halini göstermektedir. Burada PAGF' nin referans işaretleri iyi bir şekilde izlediği açıkça görülmektedir.

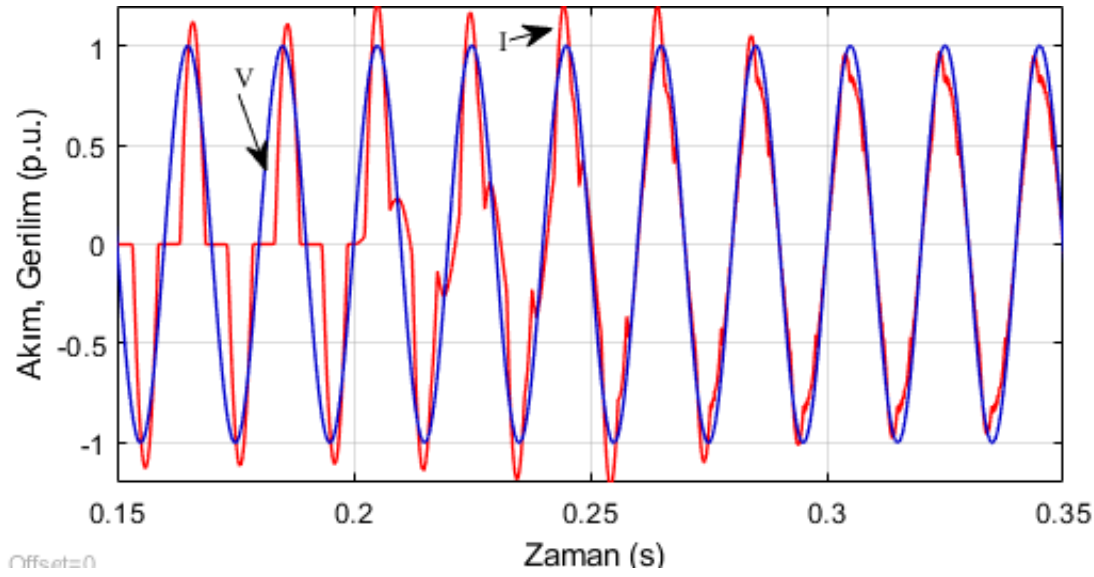

Şekil 12. PAGF kaynak, gerilim ve akım dalga şekilleri.
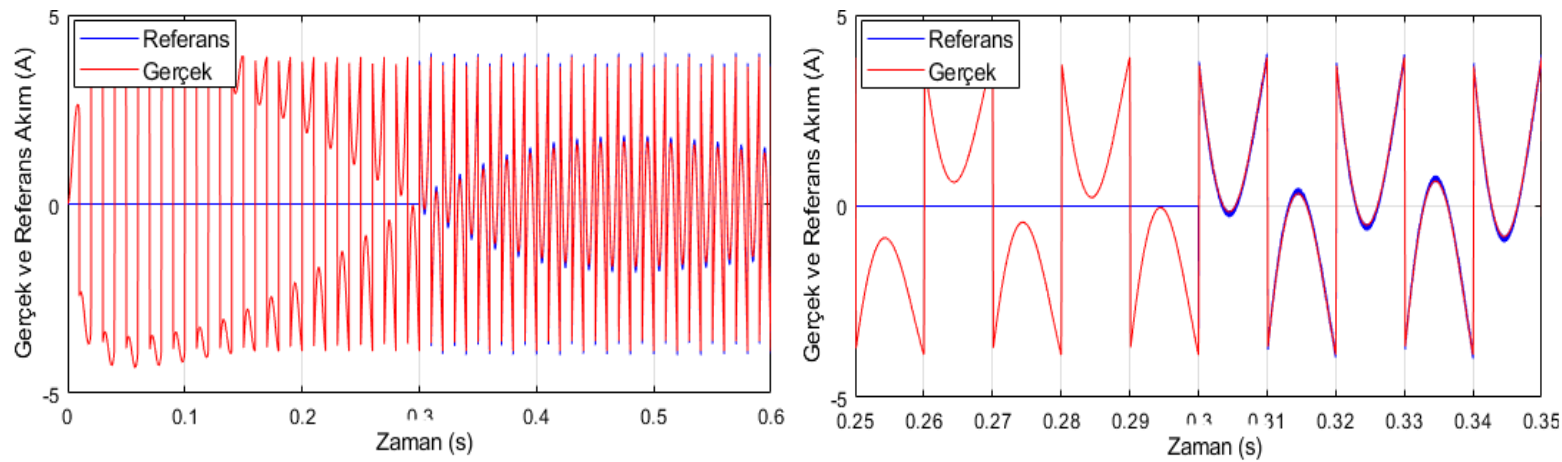

Şekil 13. PAGF’ nin referans akımı izleme performansı.

Oluşturulan devrenin doğrusal yüklerdeki davranışının incelenmesi bakımından devreye bağlanan yük değiştirilerek $\mathrm{R}=50 \Omega, \mathrm{L}=0.5 \mathrm{H}$ olan endüktif bir yük bağlanmıştır. Devre bu yük altında çalıştırılırken PAGF 0.3. saniyede devreye alındığında kaynak akımı ve gerilimi dalga şeklinin p.u. değerleri ile devreye ilişkin güç faktörü değişimi Şekil 14' de verilmiştir.

Filtrenin etkinliğinin açık bir şekilde görülmesi için yükün endüktif özelliği büyük seçilmiştir. Bu yük değerinde filtre devrede yok iken kaynak akımı ve gerilimi arasındaki faz farkı dalga şekillerinden rahatlıkla görülmektedir. Bu durumda devreye ilişkin güç faktörü 0.303 dür. Filtre devreye alındığında ise akım ve gerilim arasındaki faz farkı sıfıra yaklaşmış ve bu durumdaki güç faktörü 0.9915 olmuştur. Filtre kaynak akımı ve gerilimi arasındaki faz farkını gidererek birim güç faktörüne yaklaştırmıştır. Kaynaktan çekilen reaktif akım filtre devreye alındıktan sonra filtre tarafından sağlandığı için kaynaktan çekilen akımın da düştüğü açıkça görülmektedir.

Filtre yükünün değişiminin filtre performansına etkisini incelemek amacıyla Sistem çalışırken 0.3. saniyede filtre devreye alınmıș ve 0.5. saniyede ise mevcut yük devreden çıkarılarak farklı bir yük bağlanmıştır. Bu durumda kaynak akım ve geriliminin p.u. değerleri Şekil 15' de ve kaynak akımı, yük akımı ve filtre akımına ait dalga şekilleri Şekil 16' da sırasıyla verilmiştir. Elde edilen şekillerden tek fazlı PAGF' nin yük değişimlerinden etkilenmediği ve bu değişimlere karşı da dayanıklı olduğu görülmüştür. 

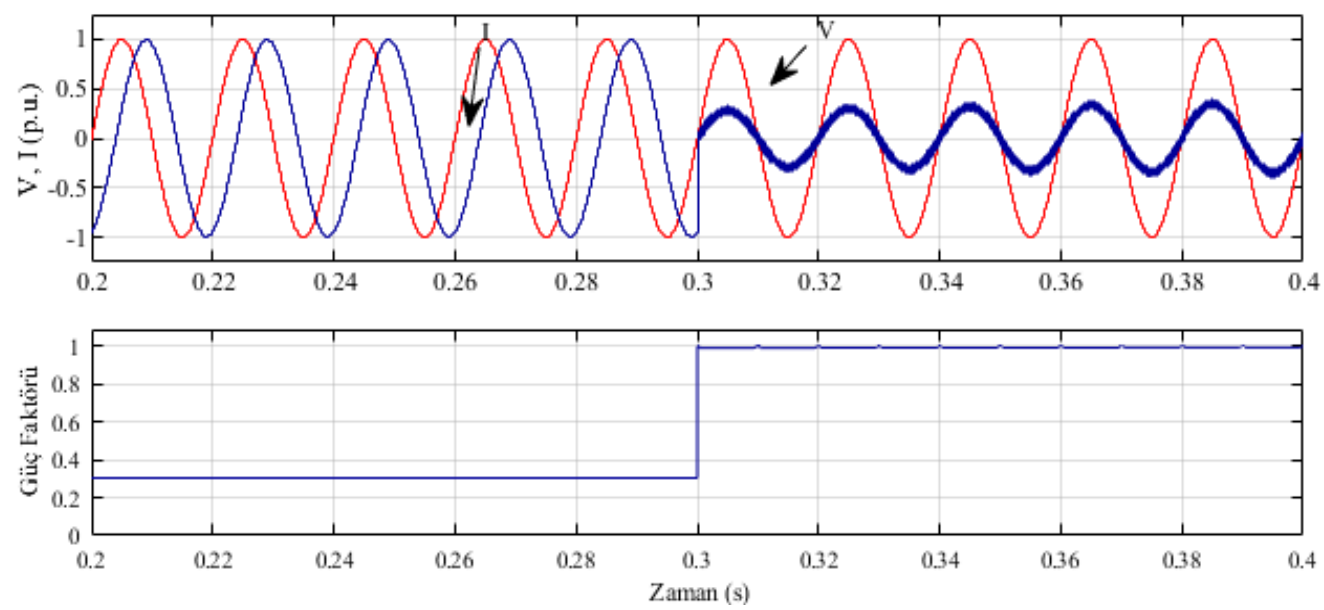

Şekil 14. PAGF' nin doğrusal yük durumundaki performansı.

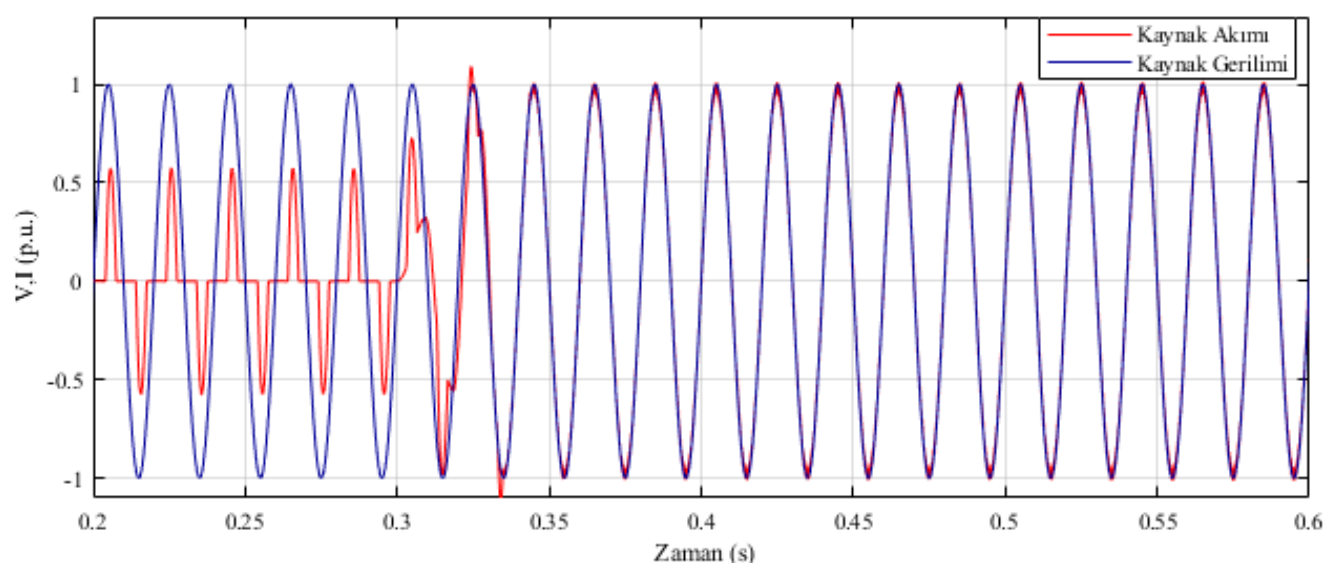

Şekil 15. PAGF’ nin doğrusal yük durumundaki performansı.
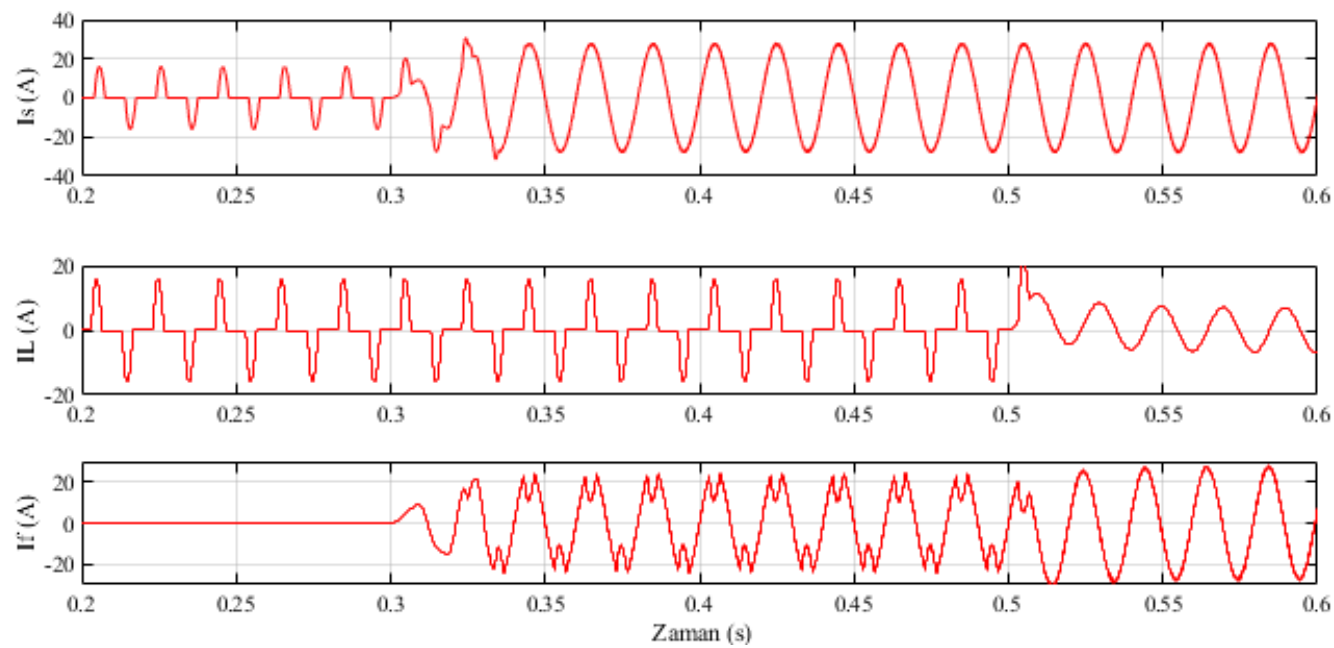

Şekil 16. PAGF' nin doğrusal yük durumundaki performansı. 


\section{Sonuçlar}

Bu makalede, bir paralel aktif güç filtresinin modeli ve denetimi yapılmıştır. Benzetimde Matlab/Simulink modelleme ortamı kullanılmıştır. PAGF modelindeki eviricinin anahtarlama elemanları için gerekli kapı işaretleri histerisiz bant akım denetleyici ile elde edilmiştir. Eviricide da bara olarak kullanılan kondansatör gerilimi ise bir PI denetleyici ile kontrol edilerek sabit tutulmuştur. Elde edilen benzetim sonuçlarından, modellenen PAGF' nin doğrusal olmayan yüklerin oluşturduğu harmonikleri bastırdığ ve reaktif gücü etkili bir şeklide kompanze ettiği görülmüştür. PAGF modeli doğrusal yüklerde de sistemin güç faktörünü iyileştirdiği ayrıca yük değişimlerinden de etkilenmeyerek güç faktörünü koruduğu elde edilen sonuçlardan görülmüştür.

\section{Kaynaklar}

[1] Kochukuttan H, Chandrasckaran A. Development of a fuzzy expert system for power quality applications. Proceedings of the Twenty-Ninth Southeastern Symposium on System Theory; 1997; Cookeville, TN. 239-243.

[2] Moran LA, Dixon, JW, Espinoza, JR, Wallace, RR. Using active power filters to improve power quality. In 5th Brazilian Power Electronics Conference; 1999. 501-511.

[3] Akagi, H, Kanazawa, Y, Nabae, A. Instantaneous reactive power compensators comprising switching devices without energy storage components. IEEE T Ind Appl 1984; 3: 625-630.

[4] Singh, B, Al-Haddad, K, Chandra, A. A review of active filters for power quality improvement. IEEE T Ind Electron 1999; 46: 960-971.

[5] Watanabe, HE, Akagi, H, Aredes, M. Instantaneous p-q power theory for compensating nonsinusoidal systems. In: International School on Nonsinusoidal Currents and Compensation; 10-13 June 2008; Lagow, Poland. 1-10.

[6] Kale, M, Özdemir, E. Harmonic and reactive power compensation with shunt active power filter under non-ideal mains voltage. Electr Pow Syst Res 2005; 74: 363-370.

[7] Bayındır, KÇ. Modelling of custom power devices. PhD Thesis, Çukurova University, Adana, Turkey, 2006.

[8] Habrouk, ME, Darwish, MK, Mehta, P. Active power filters: A review. IET Electr Power App 2000: 147(5): $403-413$.

[9] Kale, M, Özdemir, E. A new hysteresis band current control technique for a shunt active filter. Turkish Journal of Electrical Engineering\&Computer Sciences 2015; 23(3): 654-665.

[10] Buso, S, Malesani, L, Mattavelli, P. Comparison of current control techniques for active filter applications. IEEE T Ind Electron 1998; 45: 722-729.

[11] Kazmierkowski, MP, Malesani, L. Current control techniques for three-phase voltage source PWM converters: a survey. IEEE T Ind Electron 1998; 45: 691-703.

[12] Haque, MT. Single-phase pq theory for active filters. In: 2002 IEEE Region 10 Conference on Computers, Communications, Control and Power Engineering; 2002. 1941-1944.

[13] Khadkikar, V, Chandra, A, Singh, BN. Generalised single-phase pq theory for active power filtering: simulation and DSPbased experimental investigation. IET Power Electron 2009; 2(1): 67-78.

[14] Haque, MT, Ise, T. Implementation of single-phase pq theory. In: Proceedings of the Power Conversion ConferenceOsaka 2002 (Cat. No. 02TH8579); 2002. 761-765.

[15] Mattavelli, P. A closed-loop selective harmonic compensation for active filters. IEEE T Ind Appl 2001; 37: 81-89.

[16] Chandra, A, Singh, B, Singh, BN, Al-Haddad, K. An improved control algorithm of shunt active filter for voltage regulation, harmonic elimination, power-factor correction, and balancing of nonlinear loads. IEEE T Power Electr 2000; 15(3): 495-507.

[17] Nabae, A, Takahashi, I, Akagi, H. A new neutral-point-clamped PWM inverter. IEEE T Ind Appl 1981; 5: 518-523.

[18] Bhattacharya, S, Veltman, A, Divan, DM, Lorenz, RD. Flux based active filter controller. IEEE T Ind Appl 1999; 32(3): 491-501.

[19] Chen, CL, Lin, CH. An active filter for an unbalanced three-phase system using the synchronous detection method. Electr Pow Syst Res 1996; 36: 157-161.

[20] Pan, CT, Chang, TY. An improved hysteresis current controller for reducing switching frcquency. IEEE T Power Electr 1994, 9: 97-104.

[21] Malesani, L., Rosseto, L., Tomasin, P., Zuccato, A. (1996). Digital hysteresis current control with clocked commutations and wide operating range. IEEE Trans. Ind. Appl., 32: 260-268. 